\title{
REVIEW ON: COMPANY STRATEGIC COMPETITIVE POWER
}

\author{
Dharmawaty Djaharuddin, SE., M.Si. \\ Sekolah Tinggi Ilmu Ekonomi Bongaya, Makassar South Sulawesi, Indonesia
}

Prof. Dr. Abd. Rahman Kadir, SE., M.Si.

Professor of Economic, Graduate School of Economics Hasanuddin University, Makassar South Sulawesi, Indonesia

\author{
Dr. Indriyanti Sudirman, SE., M.Si.
}

Ph.D of Economic, Graduate School of Economics Hasanuddin University, Makassar South Sulawesi, Indonesia

\section{Dr. Ismail Pabo, SE., M.Si.}

Ph.D of Economics, Graduate School of Economics Hasanuddin University, Makassar South Sulawesi, Indonesia

DOI: 10.31364/SCIRJ/v6.i6.2018.P0618537

http://dx.doi.org/10.31364/SCIRJ/v6.i6.2018.P0618537

\begin{abstract}
In an organization there is a purpose that terikikulasi as well as the mechanism set to achieve that goal. Effective organizations can create and maintain a viable market for their products. Conversely, ineffective organizations will fail in selfdetermination in the marketplace. Organizations must continually modify and improve mechanisms to achieve their objectives by reorganizing the role structure and relationships and their decision-making and control processes. Efficient organizations establish mechanisms that can support their market strategy, otherwise inefficient organizations will continue to experience difficulties in terms of their mechanisms and processes. Strategies can be identified on the basis of most elements of the organization's orientation to market product development. Miles and Sow's (1978) argue that there are four types of strategies (prospectors, defenders, analyzers, reactors) and their correlations, not processes used to formulate and implement strategies (Snow \& Hambrick, 1980). Choosing the strategy used is not an easy thing for a company because it must see every change that occurs from within the environment and from other terms such as the type of product offered, the target market, competitors. Miles and Snow (1978) typology of generic strategies including prospectors, defenders, analyzers, and reactors. Prospectors focus on innovation, creating new markets and imposing uncertain environments (Miles and Snow, 1986). Defenders, emphasizing cost control in a stable environment, concentrate on their innovative efforts on process issues. analyzer builds a solid foundation in efficiency but continues to pursue incremental innovation through flexibility. reactors late to change often late and usually perform below the industry average (Brunk, 2003). This study aims to: (1) understand adaptive cyle of the organization to its environment, (2) to explain the alternative forms of adaptive behavioral strategic types, (3) to diagnose the relationship between the organization and its environment that utilizes the existing cycle, (4) to increase the attention or concern over the extent of the diagnosis organizational success and change the direction of the manager's theory of how people can and should manage, (5) create a conceptual basis for testing organizational change.
\end{abstract}

Keywords: strategy, competitiveness, strategic, environment, defender, prospector, analyzer, reactor.

\section{Introduction}

In the business world, the term strategy demonstrates "a unified, broad, and integrated plan that links the company's strategic advantage with environmental challenges and is designed to ensure that the company's ultimate goal can be achieved through proper implementation by the organization. Strategy is a means for the organization to achieve its goals.

In an organization there is a purpose that terikikulasi as well as the mechanism set to achieve that goal. Effective organizations can create and maintain a viable market for their products. The failure of an ineffective organization will fail in selfdetermination in the marketplace. Organizations must continually modify and improve mechanisms to achieve their objectives by reorganizing the role structure and relationships and their decision-making and control processes. Efficient organizations establish 
mechanisms that can support their market strategy, whereas inefficient organizations will continue to experience difficulties in terms of mechanisms and processes.

Strategies can be identified on the basis of most elements of the organization's orientation to market product development. Miles and Sow's (1978) argue that there are four types of strategies (prospectors, defenders, analyzers, reactors) and their correlations, not processes used to formulate and implement strategies (Snow \& Hambrick, 1980).

Choosing the strategy used is not an easy thing for a company because it must see every change that occurs from within the environment and from other terms such as the type of product offered, the target market, competitors. Many strategies are chosen to run the business to achieve the targets set by each company. One of the most important strategies is the competitive strategy. Miles and Snow (1978) divide four typologies of competitive strategy, namely prospector, defender, analyzer and reactor.

Miles and Snow (1978) typology of generic strategies including prospectors, defenders, analyzers, and reactors. Prospectors focus on innovation, creating new markets and imposing uncertain environments (Miles and Snow, 2009). Defenders, emphasizing cost control in a stable environment, concentrate on their innovative efforts on process issues. analyzer builds a solid foundation in efficiency but continues to pursue incremental innovation through flexibility. reactors late to change often late and usually perform below the industry average (Brunk, 2003).

According to Simon (1987), there are several reasons for choosing Miles and Snow typologies: (1) the type of prospector and defender have characteristics that use the archetype that corporate strategy is a planned decision to survive and adapt to the environment. In addition, the type of prospector and defender is related to the choice of maximizing performance or minimizing costs or relating to new inventions and pioneers in creating products and services. (2) Miles and Snow's strategy typology clearly states that the company's control system must be in line with the strategy, 3) Miles and Snow's strategy typology has been tested in various studies and found or used as a generic strategy in various industries.

This study aims to: (1) understand adaptive cyle of the organization to its environment, (2) to explain the alternative forms of adaptive behavioral strategic types, (3) to diagnose the relationship between the organization and its environment that utilizes the existing cycle, (4) to increase the attention or concern over the extent of the diagnosis organizational success and change the direction of the manager's theory of how people can and should manage, (5) create a conceptual basis for testing organizational change.

Strategy refers to the desires of how a particular goal should be achieved, while corporate strategy is defined as the company's efforts in directing its resources to achieve its goals (niclols, 2010).

\section{Strategy}

The business environment is dynamic in terms of constant change or change is constant. These environmental changes must be faced by all business and non-business organizations. Because the existence of organizations and individuals depends on its ability to adjust quickly and follow the rhythm of change (Tsiakkiros and Pashiardis, 2002). In order to survive in the face of the environment, then for corporate goals then every company or organization needs to adapt its strategy as a weapon. The right strategy will not only fortify the company to react or respond to changes in the environment, but also enable the company to proactively create change.

Thus, organizations should look for alternative solutions to survival. Strategic planning is a concept widely applied by organizations to deal with the uncertainty and changes in environmental turbulence. Changes in the external environment encourage the organization to reorganize its internal environment.

Business strategy typologies, developed and used as a theoretical basis for identifying strategic groups, frameworks that define some of the generic competitive strategies available to business units (Zahra and Covin, 1993. Generic typologies assume that strategic groups naturally appear in every industry. One of the supporting arguments to which their existence is 
described by Dranove et al. (1998) stresses the need to separate group effects on the performance of organizations and industrial effects.Some scholars have challenged this idea, however, on both conceptual and empirical reasons (Barney and Hoskisson, 1990).

Of the various proposed strategic typologies, people from Porter (1980) and Miles and Snow (1978, 1986) have received the earliest scientific attention (Veett et al., 2009). It should be noted that others have since proposed various competitive typologies, some typical and others based on previously developed frameworks (see Garrigos-Simon et al., 2005; Nwokah, 2008). Currently, both Porter and Miles and Snow's original typology remain one of the most cited, tested, and perfected.

Many early strategic group researches were conducted in developed countries such as the United States and Britain. Strategic groups and generic strategies can be applied to industries in different countries as well, but the strategy conceptualization can vary across countries, for example, in ancient China, a strategy called tactics.

\section{Business Strategy}

In the management literature we often find the term "strategic planning," strategic management, "business strategic process," or "corporate strategy." It is difficult to find a generally accepted definition of strategy since the term was imposed in business and management in the 1960s. an. Many authors interpret these terms more or less saman. The strategy comes from the Greek "strategos" which means the art of a general. Now, the term strategy is used to describe the steps an organization takes in achieving goals and for example (Tsiakkiros and Pashiaridis, 2002). The strategy is defined as a way in which the organization will reach its goals in conjunction with the opportunities and threats of the external environment encountered and in accordance with the resources and capabilities of its internal environment. From the definition there are three factors that have an important influence on the strategy, namely external circle, internal resources and capabilities, as well as goals and targets to be achieved. The point is that a strategy for the organization will provide an understanding of how the organization will compete and survive.

\section{Business Strategy Type from Miles and Snow}

The dynamic process of adjusting for the most complex environmental changes and uncertainties by most organizations involves various decisions and behaviors at various levels within the organization. But the complexity of the adjustment process can be penetrated or penetrated by looking for exemplary patterns in organizational behavior, one can describe and even predict the process of organizational adaptation. In detail, the theoretical model kits have two main elements: (1) a general model of the adaptation process underlying a number of decisions required by the organization to match its conformity to the environment and (2) the strategy strategy of the organization to illustrate different patterns of adaptive behavior used in a industry (industry group). For organizations that succeed in making changes need to be added in the theoretical framework: management theory. There are three ideas that are research podasi and studies that evolve in organizational adaptation: (1) organizational activities create their environment, (2) management strategic choice to form organizational structure and process, (3) structure and process become strategic constraint. This study aims to: (1) understand the adaptive cyle of the organization to its environment, (20) to explain the alternative forms of adaptive behavioral strategic types, (3) to diagnose the relationship between the organization and its environment that utilizes the existing cycle, (4) to increase the attention or concern over the extent of organizational diagnosis which succeeds and changes the direction of the manager's theory of how people can and should manage, (5) creates a conceptual basis for testing organizational change.

\section{Adaptation Cycle}

Miles and Snow (1978) developed a model of adaptation prose which became known as adaptive cycle. The essence of an organizational adaptation cycle is that partial organizational behavior is determined solely by environmental conditions and that decision choices made by top managers are critical determinants of organizational structures and processes. Although the 
choices are many and complex, they are seen as three major problems of organizational adaptation: entrepreneurial issues, engineering problems and admistrative matters.

\section{Entrepreneurial Problem (Entrepreneurial Problem)}

In new organizations and organizations that are already in place, solutions to entrepreneurial problems are characterized by management's acceptance of the domains of particular market products and this acceptance becomes clear when management decides to tie resources to achieve relative goals on the market domain of the product. Miles and Snow (1978) say in organizations, internal and external commitments to entrepreneurial solutions are sought for the development and projection of an organization's "image or image" that defines both the target market and its orientation toward that target market (eg emphasis on firm size, efficiency or innovation). The entrepreneurial function is the responsibility of the organization's top management, although the identification of new opportunities and drivers toward those opportunities comes from lower managerial levels.

\section{Technical Problems (Engineering Problem)}

Engineering issues include technical goal-setting dimensions and technical breadth to create a system that leads to entrepreneurial managerial solutions into action or concrete operations that include technical selection in the production and distribution process. Problems and solutions of the technical goals of an organization to gain competitive advantage include whether the organization places greater emphasis on aspects of flexibility and process innovation, cost efficiency, to build technical synergies in the operations process or whether to adjust to the problems the company is facing. While the problem and solution of technical breadth includes whether the organization is more emphasis on the breadth of ability or skill (variety or specialization), to build a synergism or whether just to try a certain technical capability.

When the solution to engineering problems has been achieved, the initial implementation of the new administration system can be run. There is no assurance that the form or configuration of the organization that emerged during the engineering phase will remain the same when the problems that arise during the engineering phase will remain the same when the engineering problem has finally been solved. The actual form or configuration of the organizational structure will be determined during the administrative phase when management strives to link to its environment, and establishes structures and processes for coordinating and controlling internal operations.

\section{Administrative Problem}

Administrative problems are primarily to reduce uncertainty within the organizational system or to rationalize and stabilize activities that successfully solve problems faced by the organization during the entrepreneurial and engineering stages. Administrative troubleshooting involves more than rationalizing the developed system (reducing the uncertainty) of administrative matters as well as including the formulation and implementation of administrative processes that enable organizations to continue innovations. Conceptions of administrative matters as a very important factor in the adaptation cycle deserve further development).

Rationalization and Articulation. In an ideal organization, management will simultaneously perform at least two different functions, ie management will be able to create administrative systems (structures and processes) that can facilitate in directing the fan to monitor ongoing activity and at the same time not allowing the administration system to become entrenched that can jeopardize future innovation activities. Perspectives such as embedding the proper admintration system, are viewed as either a langging variable or a leading variable in the adaptation process. As a lagging variable (altitude), organizations must be rational in the development of appropriate structures and processes, since strategic decisions are made to improve the adaptation process. As a leading variable, the adiminstration system should facilitate the organization's future ability to adapt itself by articulating and reinforcing the flow during innovative in-process activities. 
Although there are similarities in typology from various aspects of organizational behavior (andesrson and Paige, 1975, Ansoff, 1965 and Brandenburg, 1971, Miles and Snow 1978, Rogers 1971), Miles and Snow's formulations specify the direct link between strategy, technology, structure and the process by which the whole organization can be viewed as a whole and integrated in a dynamic interaction with its environment.

\section{a. Type Defender}

Defender or end user strategy is run by organizations that have a narrow market product domain. Top managers of this type of organization must be highly skilled within the organization's operating areas, but are less likely to seek opportunities outside the domain. As a result of this narrow focus, organizations will rarely make major adjustments in technology, structure and methods of operation. But more emphasis on attention improve the efficiency of existing operations.

Defenders (Miles \& Snow, 1978), are organizational strategies that emphasize the use of stability strategies, and business survival. The company maintains its core business or core business, without much change. Organizational leaders' attention to long-term stability

So companies that implement defenders strategy emphasize efficiency and low cost, lower than their competitors. Emphasis on efficiency is seen in strictly controlling costs.

Defender-type companies tend to limit their types of production or market restrictions. The company's performance is based on financial, production and technical engineering emphasizing expenditure on marketing and research and development $(\mathrm{R}$ \& D). In the domain of a limited market product line defenders work hard aggressively to prevent competitors from entering their "grassland". Such behavior includes standard economic measures such as competitive pricing or high-quality products, but defenders also tend to ignore developments and trends outside their domain, preferring instead to grow through market penetration and possibly the development of some limited products. From time to time defenders are able to work hard and maintain a niche or niche market within the industry that makes it difficult to penetrate by competitors.

\section{b. Prospector Type}

Prospector is almost the inverse of defenders. Companies that adopt this strategy tend to emphasize creativity and flexibility over efficiency in order to respond quickly to changing market conditions and take advantage of new opportunities. The organizational structure of the company's prospectors is informal and decentralized for more flexibility and quick response to environmental change (Stathakopoulos, 1998).

As prospectors, organizations are almost always on the lookout for market opportunities and are always experimenting on the potential response of growing environmental trends. Organization as the creator of change and uncertainty for its competitors. But because the attention is too great on the innovation so efficiency is not fully achievable.

To implement it, organizations need to encourage creativity and flexibility. Creativity helps organizations perceive or even create new opportunities in their environment, the flexibility of making the organization able to quickly change to take advantage of these new opportunities. These organizations often enhance their creativity and flexibility by adopting a decentralized organizational structure.

\section{c. Analyzer Type}

Analyzer is almost a combination of defender and analyzer. The analyzer strategy is simply moving into a new product or new market, once its success is proven by the prospectors. Analyzer lives from imitation. They take over successful ideas from prospectors and then imitate them. Their organizational structure is complex, reflecting the characteristics of mechanistic and organic organization (Stathapoulos, 1998)

The organization as an analyzer operates on two domains of market products, stable and stable (changing) domains. In a stable domain the organization operates regularly and efficiently through the formalization of structures and processes. In an area of turbulence, top managers should pay close attention to competitors to see new ideas and adopt them when promising benefits. 
Analyzers (Miles \& Snow, 1978), are organizations that use strategies between defenders, and prospectors. This means the company is not too dare to take big risks in innovating, but still trying to create excellence in its service to the market.

Miles and snow's (1978) say defenders and prospectors appear to be at the crossroads of a series of nontinuum of adjustment strategies. Between these two extremes, the third tioe of the organization strategy is disebit analyzer. Analyzer is a unique combination of prospector and defender strategy types and presents an alternative strategy other than the prospector and defender. Organizations that implement strategy analyzers are organizations that seek to minimize risk and at the same time try to maximize the opportunity to earn a profit. Organizational change analyzers (experienced analyzers try to combine the power of prospectors and defenders into a single system. The analyzer strategy is difficult to practice, especially in industries characterized by rapid market changes and technological changes, so the best word for describing the adaptip analyzer approach is "balance".

Analyzer defines intrepreneurial problems almost identical to prospectors and defenders, how to locate and take advantage of new product and new market opportunities while simultaneously maintaining the core business of a company's product and its traditional customers. The solution analyzer for entrepreneurial problems is also a mixture or combination of prospector and defender strategies. Analyzer moves toward new products or new markets but only after the market opportunity is really known to exist. Periodic transformation of domain analyzers is achieved through imitation, adopting only the most successful product or market innovation developed by other most successful prospector organizations. At the same time, the majority of the revenue analyzer or obtained from the same products and customers as the characteristics of defenders. Thus, in order to be successful the prospector must be able to respond if it wants to follow or emulate the most successful prospector and at the same time maintain efficient operations in the domain of unchanged market products. To increase its success or growth, prospectors penetrate the market through product development and market development.

\section{d. Type Reactor}

And then the last one discussed is the strategy of reactors, ie the type of company that is more pressed by the environment, because less attention to the changes and the system of competition. Reactors simply react to environmental changes and make strategically adjust only when pressure comes. Companies of this type are more concerned with efficiency, emphasizing costs including pressing on human resources. Organizations that follow the reactor strategy do not have a consistent strategic approach, drift with environmental events, react quickly but still fail to anticipate or affect events.

Defenders, prospectors and analyzers can be proactive with regard to their environment, but the three types of strategies are proactive in different ways. At the extreme, defenders continually strive or try to develop greater efficiency in existing operations, while prospectors seek to explore environmental change in search of new opportunities. From time to time, three types of strategies (Defender, prospectors, and analyzer) form a certain pattern to respond to environmental conditions in both stable and changing environments.

Reactors (Miles \& Snow, 1978), is a type of company that is more pressed by the environment, because less attention to environmental changes and competition system. Companies of this type are more concerned with efficiency, reduce costs including pressing on human resources.

Organizations within "pospected" environments such as monopolistic or highly regulated industries, organizations can not continue to behave as unlimited reactors. Sooner or later, the organization must move toward one of the defenders, prospectors, or analyzer strategies.

Reactors are the fourth or residual form after defenders, prospectors and analyzers. The organization chose forced reactor model due to instability conditions so as to choose three other more stable modes. Three reasons for the possibility of the organization choosing mode reactors: 1) top management does not articulate organizational strategy, so that a leader's leadership does not exist in the face of the instability of this condition due to the lack of cohesive statements about the direction of the organization, 2) a frequent occurrence of non- between the structure and process of the chosen strategy, 3) other causes of 
instability and also the ultimate failure that is to maintain a structural strategy relationship that is no longer appropriate to the business environment.

\section{Application of Models}

Implementation of organizational adaptation models in trials on companies by Miles and Snow as in Alpha Electronic, Fortress Insurance, Dalton Chemicals. Analysis is based on domain decisions, technical decisions and administrative decisions. The domain decision is a [there is a consistency between perceived domains, aenacted domains, desired domains and objective domains. Technical decisions regarding the extent to which operational methods used create efficiency. Administrative decisions pertain to organizational process structures that support the implementation of strategy. Diagnosis of model implementation is done by assuming: (1) viewing the organization as a whole system, (2) emphasis on administrative decision (structure-process) as an important element in the success of organizational adaptation.

\section{The linkage of management theory to organizational strategy and structure.}

To see the relationship between management theory can be seen in the evolution of each aspect separately and then seen linkage (linkages). The evolution of the organizational form identified by Chandler is divided into 3 types: (1) Type I is the organization at an early stage where the owner who runs the owner managed is also called the intrepreneur-admistrator. In typology type I organization strategy tend to be defenders or prospector, (2) type II is an organization that has used professional administration personnel with characteristic of rationalization division of labor between divisions (funcitional structured and cebtrally controlled). The typology of this type II strategy is classified as "pure" defenders, (3) type III is an organization that links strategy with its structure, in the twenties and thirties like General Motors and Sears, made a breakthrough by transforming its organization into a decentralized Federla followed by many others to this day. Strategically typologies, type II and type III or transitional forms are also known as hybrids typically using a strategy analyzer. The controls are carried out unilaterally from the top management of the organization. Based on the framework of Chandler, organizational type I according to the traditional model. Human relations model is a traditional model emphasized on the universality of the social need for belonging and will desire to recognize. This model corresponds to the type II organization. While associated with a strategy typology, the traditionhuman relations model includes defenders and reactors. Human resources model (type III) that decision-making capacity is done in order to achieve organizational goals divided into many parts, its strategy is associated with analyzer and prospector.

\section{Mixed Strategy and Structure (Mixed Strategy and Structure)}

The mix of strategies and structures takes place as the organization changes with increasing complexity. Mix occurs in conglomerate organizations, aerospace companies, government agencies and multinational corporations (MNCs). The dynamics within the organization provide a lesson of organizational structure called organization and matrix management (tipeIII-a) due to the development of double duty assignments and integrated planning process with other parts (joint pingning). The organization is diversified but glucose.

After a more complex problem arises from the matrix organization, which is above the ability of dual assignment and joint planning approach, then the offered organization is type IV (Market-matrix organization). With this type of organization the most aggressive prospector can be accommodated, because the organization uses an internal market mechanism against which all decision makers respond, so that it can reduce the direct control (hands on control) of top management. To maintain the organization's top condition, top managers are required to create a balance of desirability in all areas of the organization.

\section{Industrial studies: The case of publishing college textbooks}


In single industry (texbook publishing industry), study on food processing industry and electronics industry and hospital. Strategy research in a single industry is done by surveying 16 publishers of college textbooks. The conclusion of this research: (1). Aspects of organizational structure and processes are closely related to the views of managers, (2) top managers show different perceptions of the challenges and opportunities facing the organization, (3) manager perceptions and the characteristics of structures and processes are closely associated with an established response pattern to the business environment. From these findings developed organizational typologies with three stable organizational forms namely: defender, analyzer and prospector and an unstable organizational form called reactor.

In nonprofit hospitals strategies focusing on organizational adaptation to the environment, the process begins with awareness of the dominant coalition of environmental change by providing adjustment and adaptation responses. These findings suggest that organizational variables such as managers' perceptions of perceptions, organizational adaptations, management theories and the influence of decisions are systematically related to organizational strategy. The most significant implication is that the perception and choice of coalitions both on the organization itself as well as external environmental conditions play an important role to link organizations to their environment.

\section{Reviews}

This review is viewed from a preliminary perspective, the contingency perspective of the contingency perspective and the perspectives of neoconti- cality. Initial preliminary, Weber (1947) mebhematikulasikan for the first time the characteristics of bureaucracy (hierarchy, position and tyranny) of the study realized from the dysfunctionalities of bureaucratic structures and processes, but even so still assume that bureaucracy universally applies to all organizational settings.

Contingency perspective in a stable business environment, a highly bureaucratic and mechanistic structure while a successful enterprise in a business environment changes organizational structure and processes to be organizational and flexible. The contingency approach views the internal aspects of an organization as a dependent variable that depends on the general environment,

Miles and Snow's typology is identified from what has happened (realized strategy), called emergent and deliberated strategy. Porter embraces another generic strategy of cost leadership, differentiation and focus, transformed into cost leadership, cost focus, differention and differention cost (Porter, 1985).

Miles and Snow's typology is identified from what has happened (realized strategy), called emergent and deliberated strategy. Porter embraces another generic strategy of cost leadership, differentiation and focus, transformed into cost leadership, cost focus, differention and differention cost (Porter, 1985).

\section{Conclusions}

Adaptation is also seen as co-alignment, is a condition that mutually adjusts, accepts and gives within an organization in large configurations. Because there is a change in the environment then the manager changed the role becomes adaptive. Managers must be able to feel, process and respond to any environmental change and adapt to the reorganization of the organization's internal structure to ensure the organization can survive effectively

Research conducted by Miles and Snow is an induction effort from a generic type search strategy. Exploratory identification gives the conclusion of the types of adaptation strategies: defender. prospector, analyzer and reactor. Although not explicitly adaptations have been associated with the theory of complexity. Although the directly elaborated structure is associated with the type of strategy with the perspective of entrepreneurship, engineering and administration, it has also linked the type of organization to the typology of strategy.

\section{Bibliography}

Hambrick, D.c., 1980, Operationalizing the concept of business level strategy in recearch. Academy of Management Review, 5:567-575 
Miles R.E \& Snow, C.C (1978), Organization Structure and Prosess, New York : McGraw-Hill Book Company.

Miles and Snow", Journal of Business Research, Vol. 58, pp. 696-704. Morgan, NA, Vorhies, DW and Mason, CH (2009), "Market orientation, marketing capabilities

Nickols, F. (2010), Three forms of strategy: corporate, competitive and strategy in general. Didtance consulting LLC. Available from http://www nickols.us/three form.pdf(accessed 10/02/2017)

Simon, R., 1987. Accounting control systems and business strategy an emperical analysis. Accounting, Organization and Society, $12: 357-374$

Snow, C.C., \& Hambrick, D.c., 1980. Measuring organizational strategies : some theoretical and methodological problems. Academy of Management Review, 5:527-538.

Terziovski, M. (2010), "Innovation practice and its performance implications in small and medium enterprises (SMEs) in the manufacturing sector: a resource-based view", Strategic Management Journal, Vol. 31 No. 8, pp. 892-902. 